\title{
NMDA Receptor-Mediated Synaptic Excitation Selectively Inhibited by Ethanol in Hippocampal Slice from Adult Rat
}

\author{
David M. Lovinger, Geoffrey White, and Forrest F. Weight \\ Section of Electrophysiology, National Institute on Alcohol Abuse and Alcoholism, Rockville, Maryland 20852
}

The effect of ethanol (EtOH) on synaptic transmission mediated by $\mathrm{N}$-methyl-D-aspartate (NMDA) and non-NMDA glutamate receptors was investigated in slices from adult rat hippocampus. Synaptic responses were elicited by stimulation of stratum radiatum and were recorded in CA1 stratum radiatum or stratum pyramidale. Population EPSPs (pEPSPs) mediated by NMDA receptor activation were isolated by application of a solution containing the kainate/quisqualate receptor antagonist 6,7-dinitroquinoxaline-2,3-dione and either low $(0.1 \mathrm{~mm}) \mathrm{Mg}^{2+}$ or $100 \mu \mathrm{M}$ bicuculline. Increasing concentrations of EtOH produced increasing inhibition of NMDA receptor-mediated pEPSPs with EtOH concentrations between 1 and $50 \mathrm{~mm}$. At a concentration of $50 \mathrm{~mm}$, EtOH inhibited NMDA receptor-mediated pEPSPS by $43 \%$; the inhibition by $100 \mathrm{~mm}$ EtOH was not significantly different from that produced by $50 \mathrm{~mm}$. Methanol and 1-butanol also inhibited the NMDA receptor-mediated pEPSPs; the potency of the alcohols for inhibition of NMDA receptor-mediated pEPSPs was 1-butanol > ethanol > methanol. pEPSPs mediated by non-NMDA glutamate receptors were isolated by the application of the NMDA receptor antagonist d,1-2-amino5-phosphonovaleric acid in the presence of $1.5 \mathrm{~mm} \mathrm{Mg} \mathrm{Mg}^{2+}$. These pEPSPs were not significantly affected by $50 \mathrm{~mm}$ EtOH, whereas $100 \mathrm{~mm}$ EtOH reduced the amplitude of these pEPSPs by $9 \%$. The observations indicate that synaptic excitation mediated by NMDA receptors in tissue from adult rat is inhibited by intoxicating concentrations of EtOH. The data are consistent with the hypothesis that EtOH-induced inhibition of EPSPs mediated NMDA receptors may contribute to the intoxicating effects of EtOH.

The neurophysiological changes associated with acute ethanol $(\mathrm{EtOH})$ intoxication are poorly understood. Previous investigations have found that intoxicating concentrations of $\mathrm{EtOH}$ can alter the firing rate of neurons or affect synaptic transmission in several areas of the mammalian CNS (Klemm, 1979; Siggins et al., 1987b). However, the cellular mechanisms that underlie these effects have not been established. In neurons from fetal mouse hippocampus maintained in tissue culture, we recently found that intoxicating concentrations of EtOH selectively inhibit the ion current activated by application of the glutamate

\footnotetext{
Received Sept. 5, 1989; revised Nov. 17, 1989; accepted Nov. 20, 1989.

We would like to thank Drs. William C. deGroat and Luis G. Aguayo for helpful discussion of the experiments performed in this study.

Correspondence should be addressed to David M. Lovinger, Ph.D., Section of Electrophysiology National Institute on Alcohol Abuse and Alcoholism, 12501 Washington Avenue, Rockville, MD 20852.

0270-6474/90/041372-08\$02.00/0
}

receptor agonist $N$-methyl-D-aspartate (NMDA) (Lovinger et al., 1989a). We also found that the potency of different alcohols for inhibiting the NMDA-activated current is linearly related to their potency for producing intoxication, suggesting that $\mathrm{EtOH}$ induced inhibition of NMDA-mediated responses may contribute to EtOH intoxication. Inhibition of responses to NMDA by EtOH has also recently been reported in other experiments on fetal neurons in tissue culture (Hoffman et al., 1989; LimaLandman and Albuquerque, 1989) or freshly isolated neurons (White et al., 1990). However, the preceding observations were made on isolated cells using exogenously applied NMDA. Thus, it has not been demonstrated that EtOH can inhibit synaptic transmission mediated by the endogenous transmitter (presumably glutamate) acting on NMDA receptors in more intact preparations from adult mammalian brain.

The recent development of antagonists selective for the kainate- and quisqualate-type glutamate receptors (Honoré et al., 1988) permits the isolation of EPSPs mediated by NMDA receptor activation in hippocampal slice from adult animals (Kauer et al., 1988; Muller et al., 1988; Andreason, et al., 1989). In the present study, we used these agents to isolate NMDA receptormediated EPSPs and examine the effect of EtOH on NMDA receptor-mediated transmission in hippocampal slices from adult rat. We also studied the effect of EtOH on excitatory transmission mediated by non-NMDA receptors. A preliminary report of these observations has been presented (Lovinger et al., 1989b).

\section{Materials and Methods}

Materials. Experiments were performed on 68 hippocampal slices made from 20 male Sprague-Dawley rats (200-350 gm) obtained from Charles River breeding farms. Bicuculline hydrochloride (-isomer) and $d, l$ amino-5-phosphonovaleric acid (APV) were obtained from Sigma (St. Louis, MO), and 6,7-dinitroquinoxaline-2,3-dione (DNQX) was purchased from Tocris Neuramin (Essex, U.K.).

Preparation of hippocampal slices. Rats were killed by decapitation, and the brains were quickly removed and placed in ice-cold medium containing (mM): $\mathrm{NaCl}, 124 ; \mathrm{KCl} \mathrm{3} ; \mathrm{MgCl}_{2}, 1.5 ; \mathrm{CaCl}_{2}, 3 ; \mathrm{NaHCO}_{3}, 26$; $\mathrm{NaH}_{2} \mathrm{PO}_{4}, 1.2$; and D-glucose, 10. The medium was equilibrated with $95 \% \mathrm{O}_{2} / 5 \% \mathrm{CO}_{2}$. Hippocampi were removed, and $400 \mu \mathrm{m}$ slices were cut along the plane of the lamellar circuit (Anderson et al., 1971) using a Vibroslice model 752 (World Precision Instruments, New Haven, CT). Slices were then transferred to a beaker containing oxygenated medium at room temperature and were allowed to stabilize for at least $1 \mathrm{hr}$ before beginning recording.

Electrophysiologic recording and drug application. Field potentials were recorded in slices submerged in oxygenated medium at $32-34^{\circ} \mathrm{C}$. Medium superfused the slices at a rate of $2-3 \mathrm{ml} / \mathrm{min}$. Field potentials were evoked using bipolar stimulating electrodes made from two twisted Teflon-coated stainless steel wires (each with a diameter of $\sim 50 \mu \mathrm{m}$ ), insulated except for $\sim 1.0 \mathrm{~mm}$ at each tip, and placed in stratum radiatum near the border of the CA $2 / \mathrm{CA} 1$ subfields. Stimuli consisted of $0.02 \mathrm{msec}$, constant voltage $(15-40 \mathrm{~V})$ pulses delivered at a frequency of $0.05-0.1 \mathrm{~Hz}$. Field potentials were recorded using a micropipette filled 

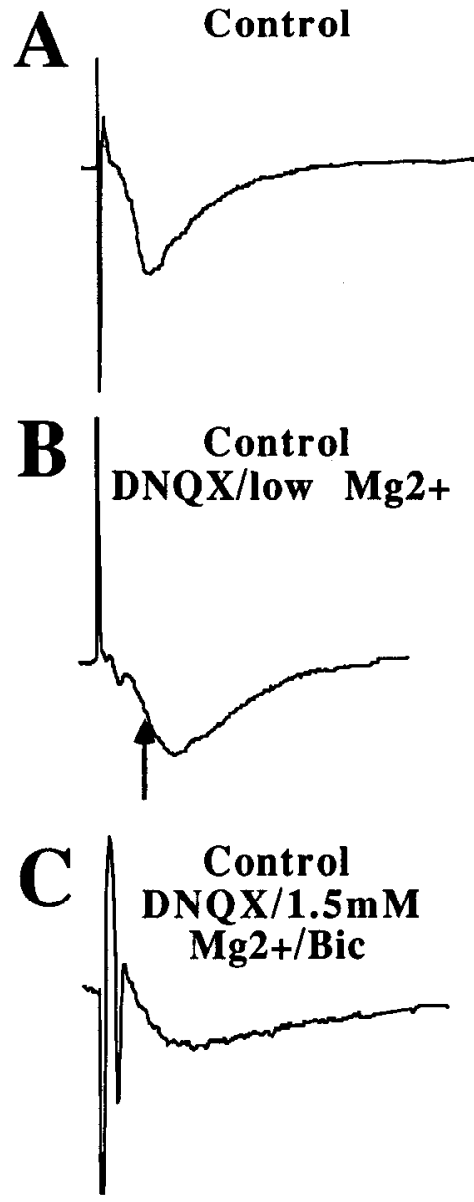

DNQX/low Mg2+
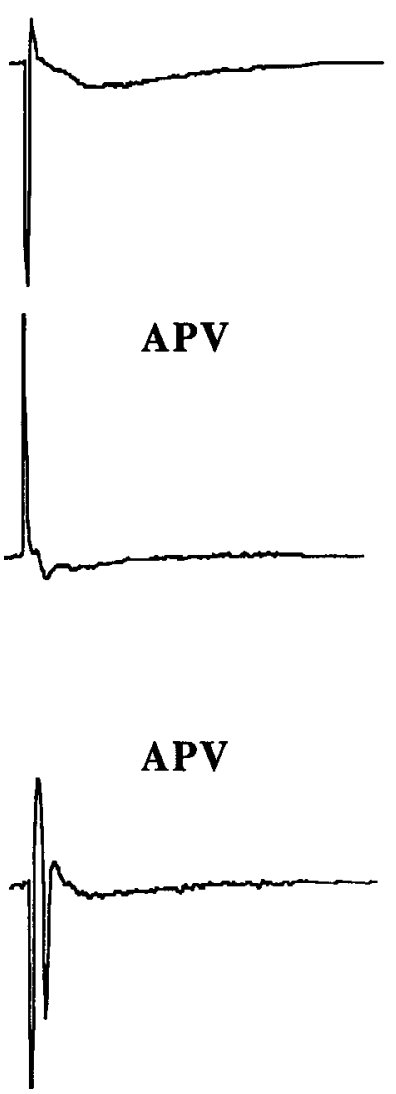

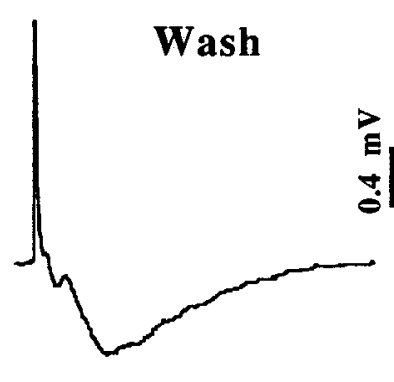

DNQX/low Mg2+ Increased Stim.
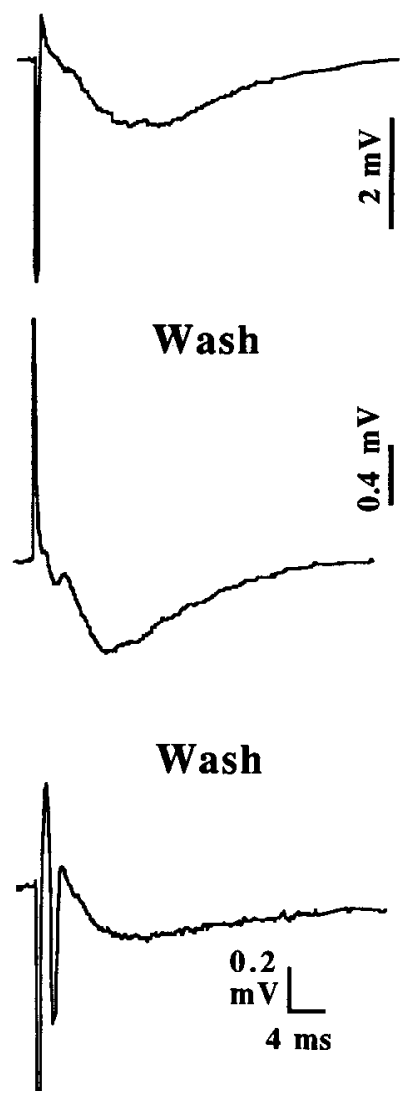

Figure 1. Isolation of NMDA receptor-mediated EPSPs using DNQX and low $\mathrm{Mg}^{2+}$ or bicuculline. A: Lefi, pEPSP evoked by single-pulse stimulation of Schaffer collateral/commissural fibers and recorded from stratum radiatum of hippocampal subfield CA1 in "physiological" solution containing $1.5 \mathrm{~mm}$ $\mathrm{Mg}^{2+}$. Center, pEPSP evoked using the same stimulus parameters in the same slice during bath application of $10 \mu \mathrm{M}$ DNQX and low (0.1 mM) $\mathrm{Mg}^{2+}$. Note the decreased amplitude of the pEPSP. Right, pEPSP in the same slice evoked by higher-intensity stimulus in the DNQX/low- $\mathrm{Mg}^{2+}$ solution. Note the increased duration of the pEPSP compared with control (left). B: Left, pEPSP evoked by single stimulus pulse in the DNQX/low- $\mathbf{M g}^{2+}$ solution in another slice. Center, response during bath application of $30 \mu \mathrm{M}$ APV. Right, pEPSP 15 min after beginning washout of APV. Arrow at left illustrates the time point at which measurements of pEPSP amplitude were taken. $C$ : Left, pEPSP evoked by single stimulus pulsc in the presence of $10 \mu \mathrm{M}$ DNQX, $1.5 \mathrm{~mm}$ $\mathrm{Mg}^{2+}$, and $100 \mu \mathrm{M}$ bicuculline (Bic). Center, Response in the same slice during application of $50 \mu \mathrm{M}$ APV. Right, pEPSP $10 \mathrm{~min}$ after beginning washout of APV. Note that the pEPSPs recorded in DNQX/low $\mathrm{Mg}^{2+}$ or in DNQX/bicuculline are almost completely eliminated by APV. Negative is down in all figures. Responses in $A-C$ are averaged pFPSPs $(n=10)$. Time calibration in $C$ applies to $A$ and $B$ as well. with $0.9 \% \mathrm{NaCl}$ and placed in the CAl stratum radiatum (to record pEPSPs) or stratum pyramidale (to record population spikes). Evoked potentials were digitized at $5 \mathrm{kHz}$ using a Nicolet 2090-IIIA digital oscilloscope. Digitized waveforms were displayed on-line, as well as stored and later analyzed on a PDP 11/23 microcomputer (Plessey Peripheral Systems, Rockville, MD). When recordings were made in "physiological" medium, slices were considered to be healthy and used for experiments if they fired only one population spike in response to a high-intensity stimulus. Most measurements were made on population EPSPs evoked by stimuli which did not produce a detectable population spike in stratum radiatum. The ampltiude measurements given in the text were taken at a fixed time point which was midway between the onset and the peak of the negative wave in the pre-drug control condition. This time point was used because it is usually uncontaminated by "noise" due to variable synchronous firing of action potentials by nearby neurons; thus, the measurements at this time point can be made more accurately than measurements at the peak of the negative wave where such "noise" can be observed (e.g., see Fig. 5). Measurements were taken at this time point throughout the course of a given experiment. Drugs were applied by bath perfusion. We estimate that there was a lag time of 3-5 min between the onset of such drug application and the arrival of the drug in the slice chamber. Drugs were allowed ample time to equilibrate to the desired concentration in the slice chamber, as judged by the time needed to reach a stable response in the presence of the compound. Unless otherwise noted, data are expressed as means \pm SEM. Statistical significance was determined by 1 -way ANOVA for comparing the effects of different concentrations of ethanol, unpaired $t$ test for comparing the effects of different alcohols, and repeated-measures $t$ test for comparing responses in the presence of drug to control responses in the same slice.

\section{Results}

\section{Isolation of EPSPS mediated by NMDA and non-NMDA} receptors

It has recently been demonstrated that in normal media the kainate/quisqualate receptor antagonist DNQX (10-25 $\mu \mathrm{M})$ produces a nearly complete to complete inhibition of pEPSPs in CA 1 evoked by stimulation of Schaffer collateral/commissural fibers (Kauer et al., 1988; Muller et al., 1988; Andreasen et al. 1989). We have also observed such inhibition (data not shown). However, in a low- $\mathrm{Mg}^{2+}$ solution, a pEPSP persists in DNQX that is completely blocked by the selective NMDA receptor antagonist APV (Muller et al., 1988). This APV-sensitive pEPSP is considered to be mediated by activation of NMDA receptors. Figure 1 illustrates the pharmacological isolation of the NMDA receptor-mediated pEPSP in our experiments. Figure $1 A$, control, shows a pEPSP recorded in "physiological" medium containing $1.5 \mathrm{~mm} \mathrm{Mg}^{2+}$. pEPSPs recorded under these conditions were insensitive to the application of $50 \mu \mathrm{M}$ APV. When the "physiological" medium was replaced with one containing 10 $\mu \mathrm{M}$ DNQX and $100 \mu \mathrm{M}$ (low) $\mathrm{Mg}^{2+}$, the amplitude of the pEPSP was greatly reduced and the time course of the remaining response was slower (Fig. $1 A$, middle). The slower time course of the pEPSP recorded in DNQX/low- $\mathrm{Mg}^{2+}$ is better seen upon increasing the stimulus intensity, as illustrated in Figure $1 A$, 
Figure 2. Reversible inhibition of NMDA receptor-mediated evoked potentials by EtOH. $A$ : Left, pEPSP in the presence of DNQX/low- $\mathrm{Mg}^{2+}$ solution (as in Fig. $1 B$ ) prior to application of EtOH. Center, pEPSP evoked in the same slice using the same experimental conditions during bath application of $50 \mathrm{~mm}$ EtOH. Right, pEPSP recorded $8 \mathrm{~min}$ after beginning washout of $\mathrm{EtOH}$. Note the decreased amplitude and slope of the initial rising phase of the pEPSP in the presence of EtOH. Note also that EtOH had no apparent effect on the amplitude of the presynaptic fiber volley. No significant change in fiber volley amplitude was observed in 5 slices in which it was measured (data not shown). The responses are averaged pEPSPs $(n$ $=10$ ). $B$. Graph showing amplitude of individual pEPSPs as a function of time for the experiment from which the responses shown in $A$ were taken. The bar above the points marks the time period between the time that the EtOH reached the slice and the beginning of washout. Data for responses evoked by different stimulus intensities were collected during the short period of time during which no responses are shown in the presence of EtOH. C: Left, Response evoked in Schaffer collateral/commisural pathway stimulation prior to EtOH application. Center, Response evoked using the same stimulus parameters in the EtOH. Right, Response $10 \mathrm{~min}$ after beginning washout of $\mathrm{EtOH}$. Note the decrease in the ampltiude of the population spike during EtOH application. Responses in $C$ are from a different slice than in $A$ and are averages of 10 individual responses. stratum pyramidale of subfield CA1 by same slice during application of $50 \mathrm{~mm}$
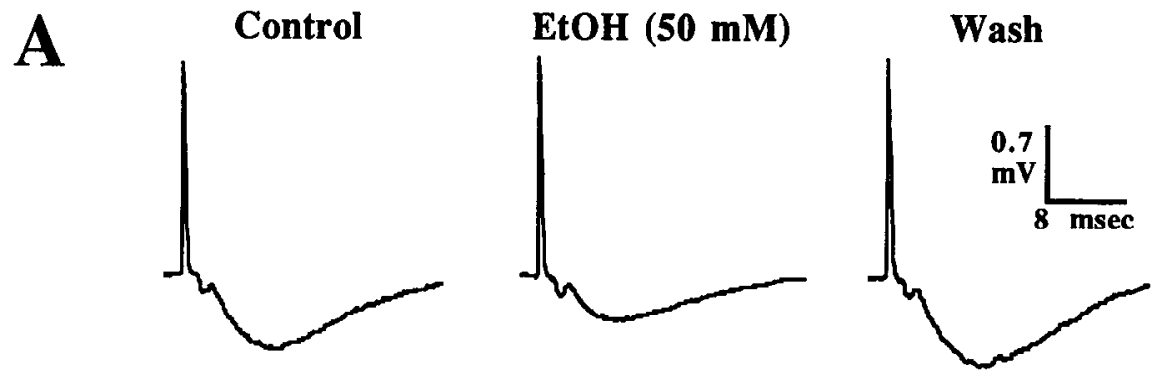

B
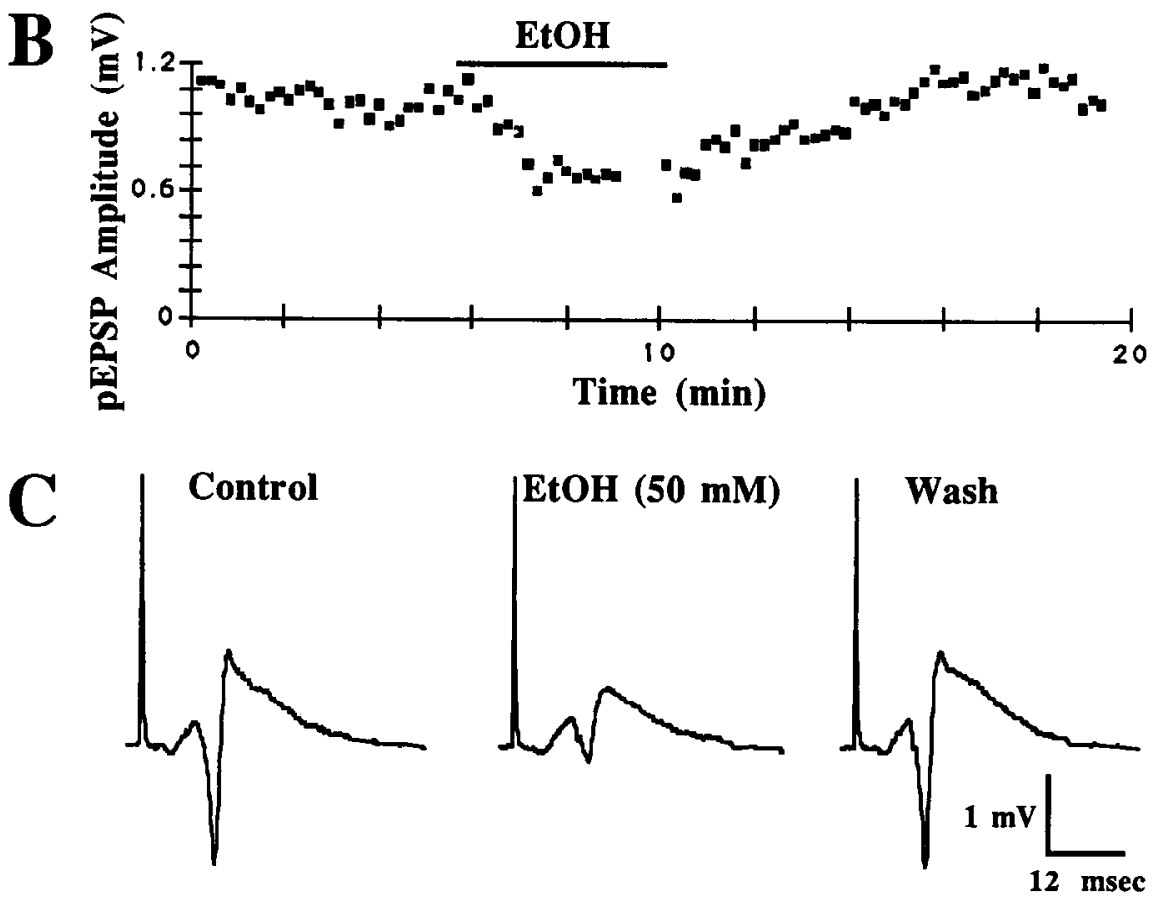

right. Figure $1 B$ shows that the pEPSP recorded in the DNQX/ low- $\mathrm{Mg}^{2+}$ solution was almost completely blocked by $30 \mu \mathrm{M}$ APV. Slow time-course, APV-sensitive pEPSPs can also be recorded in medium containing $10 \mu \mathrm{M}$ DNQX, $1.5 \mathrm{mM} \mathrm{Mg}^{2+}$, and the $\mathrm{GABA}_{\mathrm{A}}$ reccptor antagonist bicuculline $(100 \mu \mathrm{M})$ (Kauer et al., 1988). Figure $1 C$ shows a pEPSP evoked under these conditions and the antagonism of this pEPSP by $50 \mu \mathrm{M}$ APV.

\section{Effect of EtOH on EPSPS mediated by NMDA receptors}

Figure 2 illustrates the effect of $50 \mathrm{~mm} \mathrm{EtOH}$ on the NMDA receptor-mediated pEPSP (Fig. $2 A, B$ ) and the population spike activatcd by this pEPSP (Fig. $2 C$ ). The responses in Figure $2 A$ are averaged pEPSPs $(n=10)$ recorded before, during, and after the application of $50 \mathrm{~mm}$ EtOH. Figure $2 A$ shows that the am-
Figure 3. Ethanol inhibition of NMDA-mediated pEPSPs in the presence of DNQX/1.5 mM $\mathrm{Mg}^{2+}$ and bicuculline. Left, pEPSP evoked by single stimulus pulse in the presence of the DNQX/1.5 mM Mg $\mathrm{Mg}^{2+} / 100 \mu \mathrm{M}$ bicuculline solution (see text and Fig. 1 legend) prior to EtOH application. Center, pEPSP evoked in same slice using the same experimental conditions during application of $50 \mathrm{~mm}$ EtOH. Right, pEPSP recorded $12 \mathrm{~min}$ after beginning washout of EtOH. Note the decrease in the amplitude and slope of the initial rising phase of the pEPSP in the presence of EtOH. The responses are averaged pEPSPs $(n=5)$.

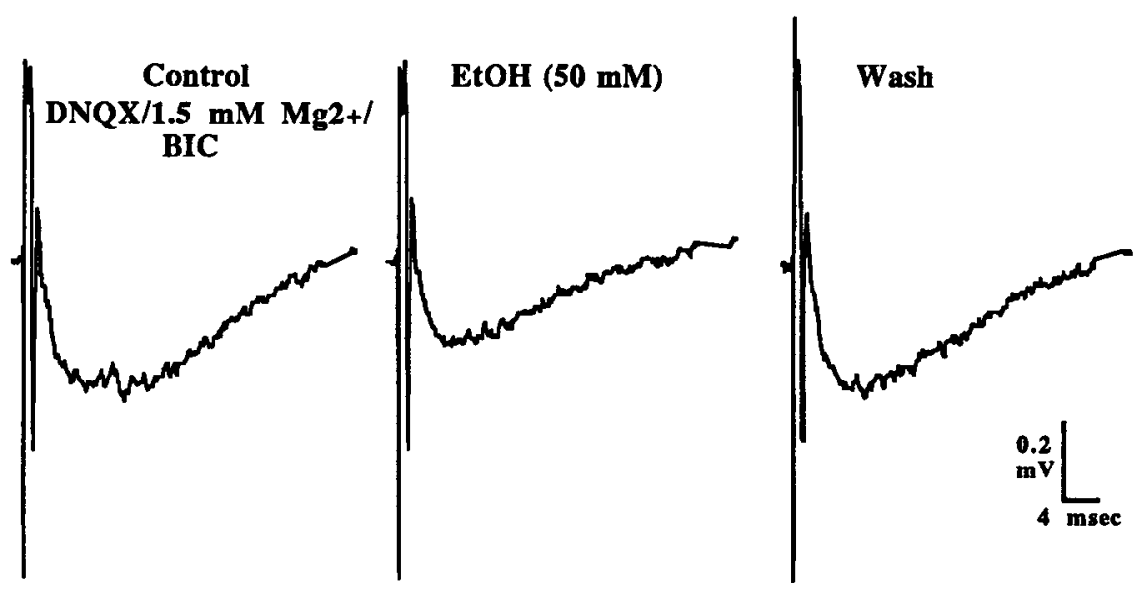


plitude of the NMDA receptor-mediated pEPSP was reduced by nearly half in the presence of $50 \mathrm{mM}$ EtOH and recovered fully after $\mathrm{EtOH}$ washout. It can also be seen that amplitude of the presynaptic fiber volley was not significantly altered in the presence of $50 \mathrm{~mm} \mathrm{EtOH}$.

The graph in Figure $2 B$ plots, as a function of time, the effect of EtOH on the amplitude of individual NMDA receptor-mediated pEPSPs; this is from the same experiment as the records in Figure $2 A$. It can be seen that the amplitude of the pEPSP began to decrease as EtOH reached the bath. The reduction in pEPSP amplitude stabilized at a maximal level within minutes after the onset of EtOH application. When $\mathrm{EtOH}$ was washed out of the recording chamber, the pEPSP gradually returned to control amplitude over several minutes. On average, $50 \mathrm{~mm}$ EtOH reduced the amplitude of the NMDA receptor-mediated pEPSP by $43 \pm 8 \%(n=9)$. With EtOH applications lasting as long as $2 \mathrm{hr} 30 \mathrm{~min}$, a similar magnitude of NMDA receptormediated pEPSP inhibition was observed over the duration of EtOH administration. In addition, even after such prolonged applications, full recovery from the effect of $\mathrm{EtOH}$ was observed $(n=2)$. Figure $2 C$ shows responses recorded in stratum pyramidale before, during, and after the application of $50 \mathrm{~mm} \mathrm{EtOH}$ under conditions designed to isolate NMDA receptor-mediated responses. It can be seen that the amplitude of the evoked population spike recorded under these conditions was greatly reduced in the presence of EtOH.

To detemine if an effect of EtOH on NMDA receptor-mediated field potentials could be observed in slices in which activation of $\mathrm{GABA}_{\mathrm{A}}$ receptors was antagonized, and in which the concentration of $\mathrm{Mg}^{2+}$ was in a more physiological range, we examined the actions of EtOH on pEPSPs recorded in DNQX, $1.5 \mathrm{mM} \mathrm{Mg}^{2+}$ and $100 \mu \mathrm{M}$ bicuculline. Figure 3 shows pEPSPs recorded before, during, and after the application of $50 \mathrm{mM}$ EtOH under these conditions. On average, $50 \mathrm{mM}$ EtOH produced a $31 \pm 4 \%(n=9)$ reduction in the amplitude of the pEPSP recorded under this condition. This result is not significantly different from the EtOH-induced inhibition of pEPSPs in the presence of DNQX and $100 \mu \mathrm{M} \mathrm{Mg} \mathbf{M g}^{2+}$ (unpaired $t=1.52$, $d f=16, p>0.05$ ). This indicates that the inhibition of the NMDA receptor-mediated pEPSPs by EtOH in the experiments carried out in low $\mathrm{Mg}^{2+}$ was not dependent on the low $\mathrm{Mg}^{2+}$ concentration. In addition, this observation also shows that EtOH was effective in reducing the amplitude of the NMDA receptormediated pEPSPs in the presence of the $\mathrm{GABA}_{\mathrm{A}}$ receptor antagonist bicuculline.

Figure $4 A$ illustrates the effect of stimulus intensity on pEPSP amplitude before and during the application of $50 \mathrm{~mm} \mathrm{EtOH}$. This curve shows that EtOH inhibited the pEPSP mediated by NMDA type receptors at all stimulus intensities tested. Thus, inhibition of the NMDA receptor-mediated pEPSP by EtOH is not a function of response amplitude or number of presynaptic fibcrs stimulated.

The graph in Figure $4 B$ illustrates the relationship between EtOH concentration and average inhibition of NMDA receptormediated pEPSPs with EtOH concentrations from 1-100 mM. With an EtOH concentration of $1 \mathrm{~mm}$, the NMDA receptormediated pEPSP decreased by $9 \pm 5 \%(n=5$; repeated-measures $t=1.889, d f=4, p>0.05$ vs control). At $25 \mathrm{~mm}, \mathrm{EtOH}$ produced a $25 \pm 2 \%(n=6)$ inhibition of the NMDA receptormediated pEPSP $(t=10.389, d f=5, p<0.0005)$. The pEPSP mediated by NMDA receptors was inhibited $43 \pm 8 \%(n=9)$ by $50 \mathrm{mM} \mathrm{EtOH}(t=4.864, d f=7, p<0.005)$. The inhibition
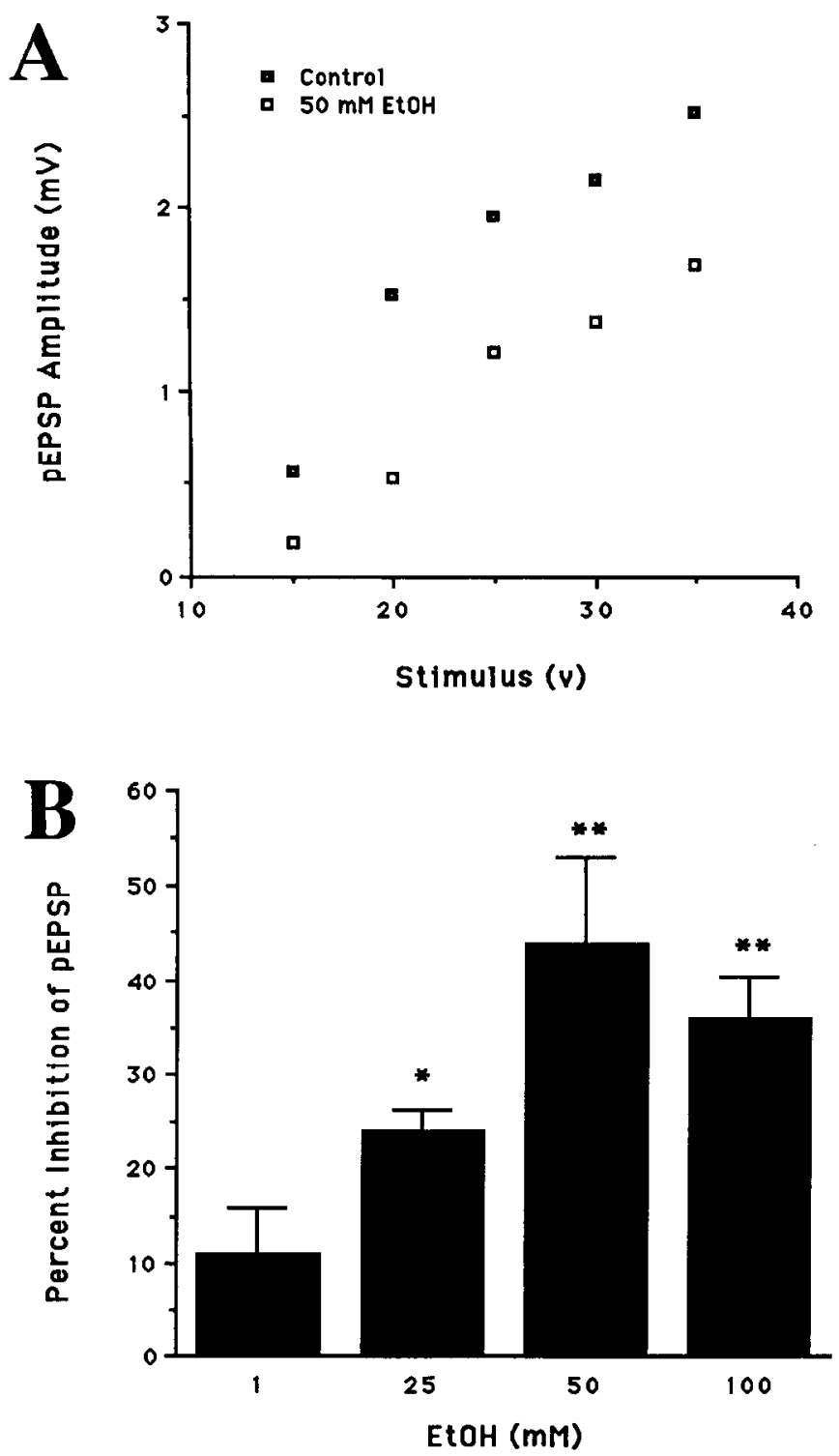

Figure 4. Graphic analysis of EtOH effect. $A$, Ethanol inhibition of NMDA receptor-mediated pEPSPs evoked over a range of stimulus intensities. Graph plotting the amplitude of the NMDA receptor-mediated pEPSPs in a single slice as a function of stimulus intensity before (filled squares) and during (open squares) application of $50 \mathrm{~mm} \mathrm{EtOH}$. $B$. Concentration dependence of EtOH inhibition of NMDA receptormediated pEPSPs. Bar graph showing the average percent inhibition (mean \pm SEM) of NMDA receptor-mediated pEPSPs by $1,25,50$, and $100 \mathrm{~mm}$ EtOH. Responses were recorded in the DNQX/low- $\mathrm{Mg}^{2+}$ solution. ${ }^{*} p<0.025$ vs baseline and $1 \mathrm{mM} \mathrm{EtOH} ;{ }^{* *} p<0.05$ vs baseline, 1 and $25 \mathrm{~mm}$ EtOH.

obscrved with $100 \mathrm{~mm}$ EtOH was $37 \pm 5 \%(n=9, t=8.304$, $d f=8, p<0.0005$ ), which is not significantly different from that observed with 50 mм $\operatorname{EtOH}(F=0.529 ; d f=1,15 ; p>$ 0.25 ).

In addition to $\mathrm{EtOH}$, we also studied the effect of 2 other alcohols, methanol and 1-butanol, on pEPSPs mediated by NMDA type receptors. Figure $5 A$ shows records of these pEPSPs before, during, and after application of $50 \mathrm{~mm}$ methanol. This concentration of methanol produced a relatively small reduction of pEPSP amplitude compared with the effect of the same concentration of EtOH (cf. Fig. $2 A$ ). On average, $50 \mathrm{~mm}$ methanol 

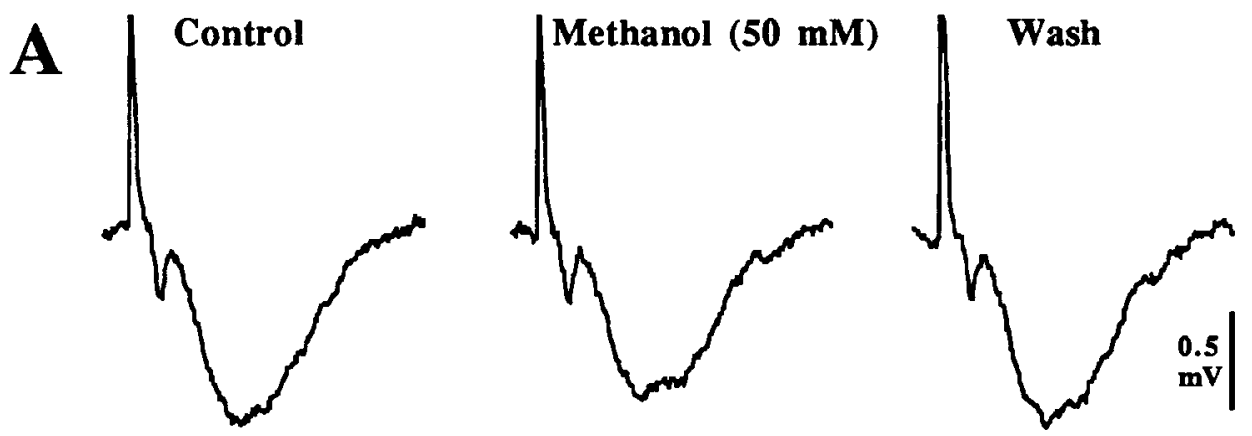

Figure 5. Inhibition of NMDA receptor-mediated pEPSPs by different alcohols. A: Left, pEPSP evoked in DNQX/low- $\mathbf{M g}^{2+}$ solution prior to methanol application. Center, pEPSP evoked in the same slice in the presence of $50 \mathrm{~mm}$ methanol. Right, pEPSP 10 min after beginning washout of methanol. B: Left, pEPSP prior to application of 1-butanol. Center, pEPSP during application of $1 \mathrm{~mm}$ 1-butanol. Right, pEPSP 12 min after beginning washout of 1-butanol. Records in $A$ and $B$ are from different slices. The responses in both $A$ and $B$ are averaged pEPSPs $(n=5)$.
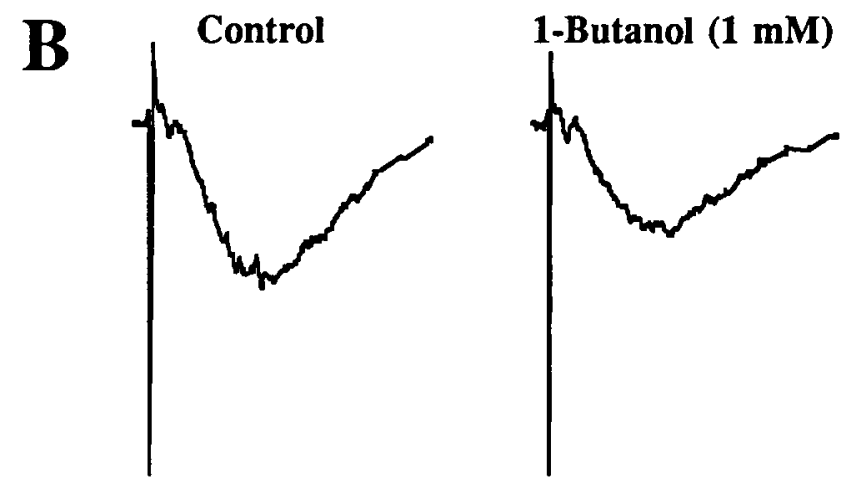

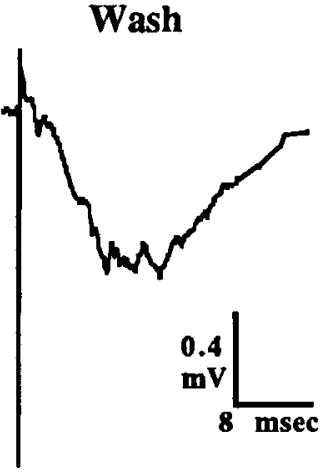

inhibited NMDA receptor-mediated pEPSPs by $17 \pm 2 \%(n=$ 6); this is significantly less inhibition than that produced by 50 $\mathrm{mM}$ EtOH (unpaired $t=2.61 ; d f=13 ; p<0.025$ ). Figure $5 B$ shows pEPSPs mediated by NMDA receptors before, during, and after application of $1 \mathrm{mM} 1$-butanol. This concentration of 1-butanol produced $27 \pm 6 \%(n=6)$ inhibition of pEPSPs mediated by NMDA receptors, which is significantly greater than the inhibition produced by $1 \mathrm{mM} \mathrm{EtOH}$ (unpaired $t=2.25$; $d f=10 ; p<0.05)$.

\section{Effect of EtOH on EPSPS mediated by non-NMDA receptors}

Recent studies indicate that in healthy hippocampal slices bathed in solutions containing physiological concentrations of $\mathbf{M g}^{2+}$, NMDA receptor activation makes little or no contribution to EPSPs elicited by low-frequency stimulation of Schaffer collateral/commissural afferents (Koerner and Cotman, 1982; Collingridge et al., 1988). Consistent with these reports, we found that the selective NMDA receptor antagonist APV had no significant effect on pEPSPs evoked by Schaffer collateral/commissural pathway stimulation in slices bathed in a normal medium containing $1.5 \mathrm{mM} \mathrm{Mg}^{2+}$. We therefore used a normal medium containing $1.5 \mathrm{~mm} \mathrm{Mg}^{2+}$ to study the effect of EtOH on pEPSPs mediated by non-NMDA receptors. We also included $50 \mu \mathrm{M}$ APV to minimize the possibility of NMDA receptor activation during the experiments. Figure $6 A$ illustrates the effects of 100 mM EtOH on pEPSPs mediated by non-NMDA receptors recorded in stratum radiatum. As can be seen, EtOH produced only a small reduction of pEPSP amplitude. Similarly, as shown in Figure $6 B$, there was little effect of $100 \mathrm{~mm} \mathrm{EtOH}$ on the population spike recorded in stratum pyramidale. This contrasts markedly with the effect of EtOH on the population spike activated by synaptic responses mediated by NMDA receptors (cf. Fig. $2 C$ ). Figure $7 A$ compares the effect of $50 \mathrm{~mm}$ EtOH on
pEPSPs under conditions which isolated NMDA (left side), and non-NMDA (right side) receptor-mediated pEPSPs. It can be seen in this direct comparison of pEPSPs of comparable amplitude that $50 \mathrm{mM}$ EtOH inhibited the pEPSP mediated by NMDA receptors, but had little effect on the non-NMDA receptor-mediated pEPSP. The graph in Figure $7 B$ shows the effect of 50 and $100 \mathrm{~mm} \mathrm{EtOH}$ on the average amplitude of pEPSPs mediated by non-NMDA glutamate receptors. In the presence of $50 \mathrm{~mm}$ EtOH, the average amplitude of the pEPSPs mediated by non-NMDA receptors was $107 \pm 11 \%(n=8)$ of control (repeated-measures $t=0.566 ; d f=7 ; p>0.1$ ). In the presence of $100 \mathrm{~mm} \mathrm{EtOH}$, the amplitude of the pEPSP mediated by non-NMDA receptors was $91 \pm 3 \%(n=6)$ of control $(t=3.329$; $d f=5 ; p<0.025$ ).

\section{Discussion}

The results reported here show that $\mathrm{EtOH}$ concentrations greater that $1 \mathrm{~mm}$ inhibited pEPSPs mediated by NMDA receptors in hippocampal slice from adult rat. Inhibition of the NMDA receptor-mediated pEPSPs increased in a concentration-dependent manner with EtOH concentrations up to $50 \mathrm{~mm}$. The inhibition by $100 \mathrm{~mm}$ EtOH was not significantly different from the inhibition by $50 \mathrm{~mm} \mathrm{ElOH}$. The concentration range over which EtOH inhibited the NMDA receptor-mediated pEPSP was roughly similar to the concentration range over which $\mathrm{EtOH}$ inhibits NMDA-activated ion current in cultured fetal hippocampal neurons (Lovinger et al., 1989a) and isolated dorsal root ganglion neurons (White et al., 1990).

The results of the present study on synaptic responses in hippocampal slice extend our previous observations (Lovinger et al., 1989a, White et al., 1990) in several ways. First, the present experiments show that EtOH selectivcly inhibits NMDA receptor-mediated responses in tissue from adult brain. Second, 
A

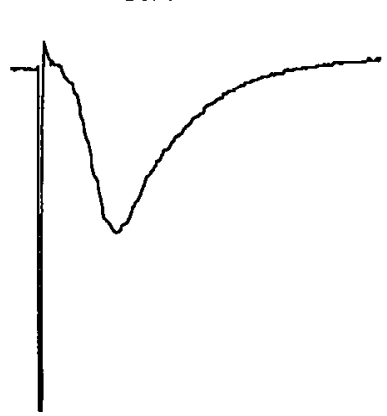

Control

B

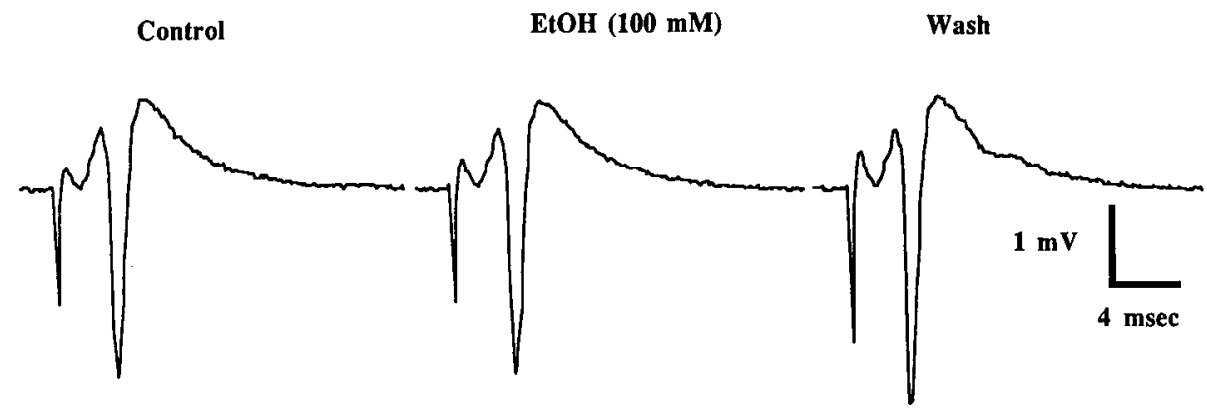

EtOH (100 mM)

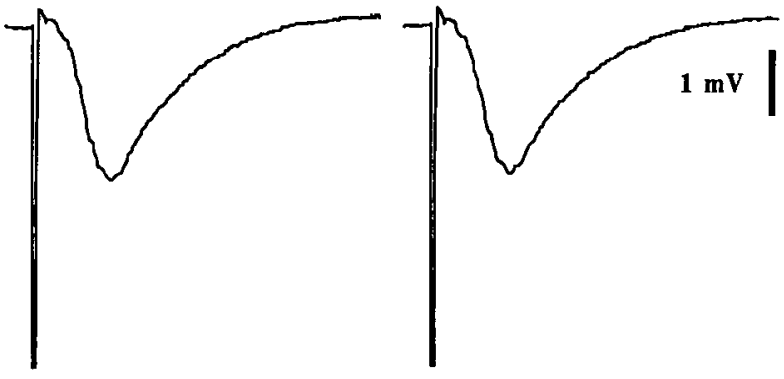

Figure 6. Effect of EtOH on responses mediated by non-NMDA glutamate recptors. A: Left, pEPSP recorded in stratum radiatum of slice in $1.5 \mathrm{mM}$ $\mathrm{Mg}^{2+} / 50 \mu \mathrm{M}$ APV solution (see text) prior to EtOH application. Center, pEPSP recorded from the same slice during application of $100 \mathrm{~mm} \mathrm{EtOH}$. Right, pEPSP recorded $10 \mathrm{~min}$ after beginning washout of EtOH. B: Left, Response, with population spike, recorded in stratum pyramidale in solution containing $1.5 \mathrm{~mm} \mathrm{Mg}^{2}$ and $50 \mu \mathrm{M}$ APV. Center, Response evoked in the same slice during bath application of $100 \mathrm{~mm}$ EtOH. Right, Response 9 min after beginning washout of $\mathrm{EtOH}$. Note that $\mathrm{EtOH}$ had little effect on the amplitude of the pEPSP or the population spike under these conditions. Records in $A$ and $B$ are from different slices. Responses in $A$ and $B$ are averaged ( $n$ $=5$ ).

A

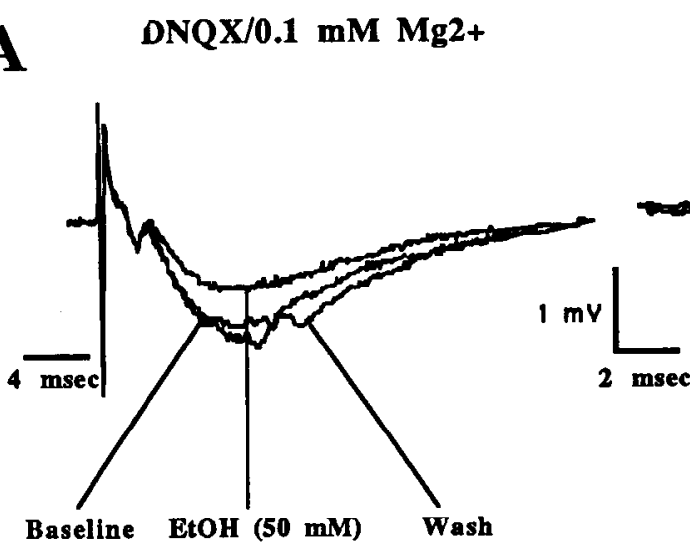

APV/1.5 mM Mg2+

B

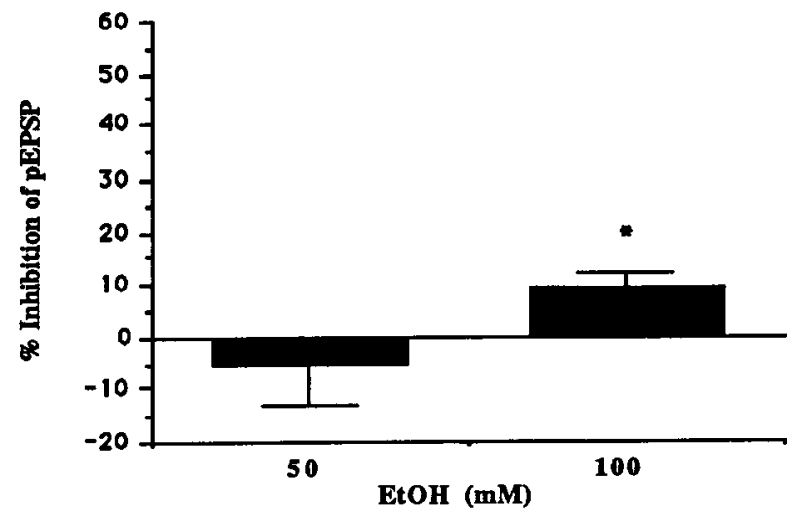

Figure 7. Effect of EtOH on pEPSPs mediated by non-NMD $\Lambda$ glutamate receptors. $A$, Comparison of NMDA and non-NMDA receptor-mediated pEPSPs of similar amplitude. Lefl, pEPSPs recorded in DNQX/low- $\mathrm{Mg}^{2+}$ solution before, during, and after application of $50 \mathrm{~mm}$ EtOH. Right, pEPSPs recorded in APV/1.5 mM $\mathrm{Mg}^{2+}$ solution before, during, and after application of $50 \mathrm{~mm}$ $\mathrm{EtOH}$. Note that although the amplitude of the pEPSPs is similar under both conditions, EtOH inhibits only the NMDA receptor-mediated pEPSP (left). The records in $A$, left, are from a different slice than the records in Figure $2 A$. The records in $A$, right, are from a different slice than the records in $A$, left. Responses are averaged pEPSPs $(n=$ 5). $B$, Average effect of $\mathrm{EtOH}$ on nonNMDA receptor-mediated pEPSPs. Bar graph showing the average percent inhibition (mean \pm SEM) of pEPSPs recorded in the presence of APV and 1.5 $\mathrm{mM} \mathrm{Mg}^{2+}$ by 50 and $100 \mathrm{~mm}$ EtOH. The effect of $50 \mathrm{~mm}$ EtOH was not statistically significant $(n=8, p>0.1)$; $100 \mathrm{~mm} \mathrm{EtOH}$, on the other hand, produced a $9 \%$ reduction of non-NMDA receptor-mediated pEPSP amplitude that was significant $\left(n=6,{ }^{*} p<0.025\right)$. 
these experiments demonstrate the $\mathrm{EtOH}$ is effective in inhibiting responses to activation of the NMDA receptor by its endogenous ligand (presumably glutamate) in a preparation more intact than the isolated neurons previously examincd. Finally, the present study shows that EtOH can inhibit electrophysiological responses to NMDA receptor activation at temperatures closer to the physiological range than the room temperature used in previous experiments.

The fact that EtOH can inhibit the ion current activated by application of NMDA to cultured hippocampal neurons (Lovinger et al., 1989a) suggests that the EtOH-induced inhibition of the NMDA receptor-mediated pEPSPs in hippocampal slice may be due to a postsynaptic action of EtOH. However, it does not exclude the possibility that in the present experiments an inhibition of transmitter release from presynaptic terminals may contribute to the reduction of pEPSP amplitude. Since the transmitter released from Schaffer collateral/commissural terminals that activates the NMDA receptor-mediated pEPSP is thought to be glutamate, it is possible to compare the effect of EtOH on pEPSPs activated by stimulation of this pathway but mediated by non-NMDA glutamate receptors. In such experiments, we found that $50 \mathrm{~mm}$ EtOH did not significantly affect the amplitude of pEPSPs mediated by non-NMDA glutamate receptors. This observation supports the idea that the inhibitory action of EtOH on the NMDA receptor-mediated pEPSP is postsynaptic. In this regard, it should be noted that $100 \mathrm{~mm} E t O H$ had a small $(9 \%)$ inhibitory action on the pEPSPs mediated by nonNMDA glutamate receptors. A small reduction in excitation mediated by non-NMDA receptors might contribute to the inhibition of EPSPs previously observed at glutamatergic synapses in rat hippocampus (Siggins et al., 1987a) and crayfish neuromuscular junction (Finger and Stettmeier 1984). Although this effect might result from a presynaptic action, it seems more likely that it is postsynaptic since this concentration of $\mathrm{EtOH}$ was found to have an inhibitory effect on both kainate- and quisqualate-activated ion currents in cultured hippocampal neurons (Lovinger et al., 1989a).

The magnitude of the EtOH-induced inhibition of pEPSPs in the present study was smaller than the inhibition of glutamate receptor-activated ion current in our previous study of cultured hippocampal neurons (Lovinger et al., 1989a). For example, 50 $\mathrm{mM}$ EtOH reduced the amplitude of the NMDA receptor-mediated pEPSP by $43 \%$ in this study, whercas it produccd a $61 \%$ reduction of NMDA-activated current amplitude in the cultured hippocampal neurons. We do not know what factors underlie this apparent difference in efficacy; however, there are a number of differences between the two preparations. First, the brain slices used in the present study were from adult rat hippocampus, whereas the cultured neurons used in the previous study were from fetal mouse hippocampus. Second, the pEPSPs in the present study were elicited in CAl pyramidal neurons, whereas the cultured neurons studied previously were not identified with respect to neuronal type. Third, in the present study the extracellular ionic environment contained a bicarbonate-buffered solution, whereas the cultured neurons were studied in a HEPESbuffered medium. Fourth, in the present study, the pEPSPs were generated in neurons with an intact intracellular milieu, whereas in the previous whole-cell patch-clamp study of cultured neurons, the cell interior was dialyzed with an EGTA- and HEPESbuffered ionic solution. Fifth, the present experiments were conducted at a temperature of $32-34^{\circ} \mathrm{C}$, whereas the previous experiments were carried out at room temperature $\left(22-24^{\circ} \mathrm{C}\right)$.
Finally, the brain slices used in the present experiments and the cultured neurons grown on a glial bed used in the previous experiments might differ with respect to the presence or absence of various factors in the external neuronal milieu. It is possible that one or more of these experimental differences contributes to the difference in the magnitude of the $\mathrm{EtOH}$-induced inhibition of glutamate receptor-mediated responses in hippocampal slice and cultured hippocampal neurons. Further work is needed to determine the factors that are involved in this difference.

It has been reported that EtOH can potentiate GABA-activated ${ }^{36} \mathrm{Cl}-$ flux in biochemical experiments (Allan and Harris, 1986; Suzdak et al., 1986; Mehta and Ticku 1988), and responses to GABA in some electrophysiological experiments (Davidoff, 1973; Nestoros, 1980; Celentano et al., 1988; but see also Mancillas et al., 1986; Harrison et al., 1987). Even though EtOH potentiation of GABA-mediated IPSPs has not been observed in hippocampus (Siggins et al., 1987a), it is important to exclude the possibility that the reduction of pEPSP amplitude by EtOH might result from potentiation of superimposed GABAmediated IPSPs. The GABA $\mathrm{A}_{\mathrm{A}}$ receptor antagonist bicuculline, in a concentration of $100 \mu \mathrm{M}$, has been shown to completely block responses to GABA in hippocampal neurons (Alger and Nicoll, 1982), as well as EtOH-induced potentiation of ${ }^{36} \mathrm{Cl}^{-}$flux in biochemical experiments (Suzdak et al., 1987). Our observation that EtOH inhibited the NMDA receptor-mediated pEPSP in the presence of $100 \mu \mathrm{M}$ bicuculline suggests that the amplitude reduction of this pEPSP by EtOH does not occur secondary to a potentiation of the $\mathrm{Cl}^{-}$current in IPSPs mediated by GABA.

Inhibition of NMDA receptor-mediated excitatory synaptic responses by $\mathrm{EtOH}$ could have a number of effects on neural mechanisms in the CNS. Several laboratories have reported evidence that activation of the NMDA receptor is involved in neural excitation (Collingridge et al., 1988) and forms of synaptic plasticity such as long-term potentiation (Collingridge et al., 1983; Harris et al., 1984). Consequently, a dccrcasc in the neural response to NMDA receptor activation would be expected to reduce the capacity for activation of such phenomena. Consistent with this suggestion, $\mathrm{EtOH}$ has been reported to alter neural excitability (Faber and Klee, 1977; Klemm, 1979; Siggins et al., 1987b) and inhibit the initiation of long-term potentiation of synaptic responses in hippocampus (Sinclair and Lo, 1986; Mulkeen et al., 1987). NMDA receptor activation has also been implicated in cognitive functions such as learning and memory (Morris et al., 1986; Staubli et al., 1989). This suggests that inhibition of NMDA receptor-mediated EPSPs by EtOH may contribute to the impairment of cognitive and neural function associated with $\mathrm{EtOH}$ intoxication.

\section{References}

Allan, A. M., and R. A. Harris (1986) Gamma-aminobutyric acid and alcohol actions: Neurochemical studies of long sleep and short sleep mice. Life Sci. 39: 2005-2015.

Alger, B. E., and R. A. Nicoll (1982) Pharmacological evidence for two kinds of GABA receptor on rat hippocampal pyramidal cells studied in vitro. J. Physiol. (Lond.) 328: 125-141.

Anderson, P., T. V. P. Bliss, and K. K. Skrede (1971) Lamellar organization of hippocampal excitatory pathways. Exp. Brain Res. 13: 208-221.

Andreasen M., J. D. C. Lambert, and M. S. Jensen (1989) Effects of new non-N-methyl-D-aspartate antagonists on synaptic transmission in the in vitro rat hippocampus. J. Physiol. (Lond.) 414: 317--336.

Celentano, J. J., T. T. Gibbs, and D. H. Farb (1988) Ethanol poten- 
tiates GABA- and glycine-induced chloride currents in chick spinal cord neurons. Brain Res. 455: 377-380.

Collingridge, G. L., S. J. Kehl, and H. McLennan (1983) Excitatory amino acids in synaptic transmission in the Schaffer collatcral-commissural pathway of the rat hippocampus. J. Physiol. (Lond.) 334: 33-46.

Collingridge, G. L., C. E. Herron, and R. A. J. Lester (1988) Synaptic activation of $\mathrm{N}$-methyl-D-aspartate receptors in the Schaffer collateral-commissural pathway of rat hippocampus. J. Physiol. (Lond.) 339: 283-300.

Davidoff, R. A. (1973) Alcohol and presynaptic inhibition in an isolated spinal cord preparation. Arch. Neurol. 28: 60-63.

Faber, D. S., and M. R. Klee (1977) Actions of ethanol on neuronal membrane properties and synaptic transmission. In Alcohol and Opiates: Neurochemical and Behavioral Mechanisms, K. Blum, ed., pp. 41-63, Academic, New York.

Finger, W., and H. Stettmeier (1984) Postsynaptic actions of ethanol and methanol in crayfish neuromuscular junctions. Pflüegers Arch. 400: $113-120$.

Harris, E. W., A. H. Ganong, and C. W. Cotman (1984) Long-term potentiation in the hippocampus involves activation of N-methyl-Daspartate receptors. Brain Res. 323: 132-137.

Harrison, N. L., M. D. Majewska, J. W. Harrington, and J. L. Barker (1987) Structure-activity relationships for steroid interaction with $\gamma$-aminobutyric acid $_{\mathrm{A}}$ receptor complex. J. Pharmacol. Exp. Ther. 241: 346-353.

Hoffman, P. L., C. S. Rabe, F. Moses, and B. Tabakoff (1989) $\mathrm{N}$-methyl-D-aspartate receptors and ethanol: Inhibition of calcium flux and cyclic GMP production. J. Neurochem. 52: 1937-1940.

Honoré, T., S. N. Davies, J. Drejer, E. J. Fletcher, P. Jacobsen, D. Lodge, and F. E. Nielsen (1988) Quinoxalinediones: Potent competitive non-NMDA glutamate receptor antagonists. Science 241: 701703.

Kauer, J. A., R. C. Malenka, and R. A. Nicoll (1988) A persistent postsynaptic modification mediates long-term potentiation in the hippocampus. Neuron 1: 911-917.

Klemm, W. R. (1979) Effects of ethanol on nerve impulse activity. In Biochemistry and Pharmacology of Ethanol, E. J. Majchrowitz and E. P. Noble, eds., pp. 243-267, Plenum, New York.

Koerner, J. F., and C. W. Cotman (1982) Response of Schaffer collateral-CA1 pyramidal cell synapses of the hippocampus to analogues of acidic amino acids. Brain Res. 251: 105-115.

Lima-Landman, M. T. R., and E. X. Albuquerque (1989) Ethanol potentiates and blocks NMDA-activated single-channel currents in rat hippocampal pyramidal cells. FEBS Lett. 247: 61-67.

Lister, R. G., M. J. Eckardt, and H. Wcingartncr (1987) Ethanol intoxication and memory. Recent developments and new directions. In
Recent Developments in Alcoholism, Vol. 5, M. Galanter, ed., pp. 111-125, Plenum Press, New York.

Lovinger, D. M., G. White, and F. F. Weight (1989a) Ethanol inhibits NMDA-activated ion current in hippocampal ncurons. Science 243: 1721-1724.

Lovinger, D. M., G. White, and F. F. Weight (1989b) Intoxicating concentrations of ethanol (EtOH) inhibit NMDA receptor-mediated EPSPs in adult rat hippocampus. Soc. Neurosci. Abst. 15: 1168 .

Mancillas, J., G. R. Siggins, and F. E. Bloom (1986) Systemic ethanol: Selective enhancement of responses to acetylcholine and somatostatin in the rat hippocampus. Science 231: 161-163.

Mehta, A. K., and M. K. Ticku (1988) Ethanol potentiation of GABAergic transmission in cultured spinal cord neurons involves $\gamma$-aminobutyric acid $_{\mathrm{A}}$-gated chloride channels. J. Pharmacol. Exp. Ther. 246: 558-564.

Morris, R. G. M., E. Anderson, G. S. Lynch, and M. Baudry (1986) Selective impairment of learning and blockade of long-term potentiation by an $\mathrm{N}$-methyl-D-aspartate receptor antagonist, AP 5 . Nature 319: 774-776.

Muller, D., M. Joly, and G. Lynch (1988) Contributions of quisqualate and NMDA receptors to the induction and expression of LTP. Science 242: 1694-1697.

Mulkeen, D., R. Anwyl, and M. J. Rowan (1987) Enhancement of long-term potentiation by the calcium channel agonist Bayer K8644 in CA1 of the rat hippocampus in vitro. Neurosci. Lett. 80: 351-355.

Nestoros, J. N. (1980) Ethanol specifically potentiates GABA-mediated neurotransmission in feline cerebral cortex. Science 209: 708710 .

Siggins, G. R., Q. J. Pittman, and E. D. French (1987a) Effects of ethanol on CA1 and CA3 pyramidal cells in the hippocampal slice preparation: An intracellular study. Brain Res. 414: 22-34.

Siggins, G. R., F. E. Bloom, E. D. French, S. G. Madamba, J. Mancillas Q. J. Pittman, and J. Rogers (1987b) Electrophysiology of ethanol on central neurons. Ann. N.Y. Acad. Sci. 492: 350-365.

Sinclair, J. G., and G. F. Lo (1986) Ethanol blocks tetanic and calciuminduced long-term potentiation in the hippocampal slice. Gen. Pharmacol. 17: 231-233.

Staubli, U., O. Thibault, M. DiLorenzo and G. Lynch (1989) Antagonism of NMDA receptors impairs acquisition but not retention of olfactory memory. Behav. Neurosci. 103: 54-60.

Suzdak, P. D., R. D. Schwartz, P. Skolnick, and S. M. Paul (1986) Ethanol stimulates $\gamma$-aminobutyric acid receptor-mediated chloride transport in rat brain synaptoneurosomes. Proc. Natl. Acad. Sci. USA 83: $4071-4075$.

White, G., D. M. Lovinger, and F. F. Weight (1990) Ethanol inhibits NMDA-activated current but does not alter GABA-activated current in an isolated adult mammalian neuron. Brain Res. (in press). 